\title{
Basolateral Amygdala Lesions Do Not Prevent Memory of Context-Footshock Training
}

\author{
Daniel J. Berlau' and James L. McGaugh \\ Center for the Neurobiology of Learning and Memory and Department of Neurobiology and Behavior, University of California, \\ Irvine, California 92697-3800, USA
}

\begin{abstract}
The present studies examined the effects of basolateral amygdala (BLA) lesions induced prior to or after context-footshock training on 48-h memory, using several retention measures. In experiment 1, male Sprague-Dawley rats with bilateral BLA lesions (NMDA, $12.5 \mathrm{mg} / \mathrm{mL}, 0.2 \mu \mathrm{L}$ ) were given footshock training in one compartment of a two-compartment alley. Rats were habituated to the alley and $24 \mathrm{~h}$ later were given two footshocks in the shock compartment. Retention was tested $48 \mathrm{~h}$ later, using latency to enter the shock compartment and time spent freezing as measures of memory. Two days later, they were tested again and received a footshock on each re-entry of the shock compartment prior to remaining in the safe compartment for 200 consecutive seconds. The BLA lesions did not block retention as assessed by freezing or number of re-entries of the shock compartment. In experiment 2 , no prior habituation was given, and only one footshock was used for the training. BLA lesions did not block retention, as indicated by latencies to enter the shock compartment on a 48-h test or by number of entries of the shock compartment. Experiment 3 examined the effects of the $G_{A B A}$ agonist muscimol infused into the BLA prior to the 48-h retention test. The muscimol infusions decreased retention test entrance latencies but did not block retention as assessed by the number of subsequent entries of the shock compartment. These findings provide additional evidence that an intact BLA is not required for the acquisition or retention of context-footshock training.
\end{abstract}

It is well established that, in rats, inactivation or lesions of the basolateral amygdala (BLA) decrease freezing behavior elicited by cues previously associated with footshock (Kim et al. 1991; Phillips and LeDoux 1992; Maren et al. 1996a; Maren 1998). Such findings have indicated that the BLA may be a critical locus of neuroplasticity underlying the memory of Pavlovian fear conditioning, as freezing behavior (defined as the cessation of all motion except respiration) is typically used as the measure of memory in such experiments (LeDoux 1995; Maren and Fanselow 1996; Davis et al. 1997; Schafe et al. 1999). However, there is extensive evidence that lesions or drug-induced inactivation of the BLA also increase locomotor activity and decrease indices of unconditioned fear in rats, including freezing behavior (Blanchard and Blanchard 1972; Ambrogi-Lorenzini et al. 1991; Burns et al. 1996; Vazdarjanova et al. 2001; Power and McGaugh 2002). Thus, the impairment of conditioned freezing induced by treatments that disrupt BLA functioning cannot be unambiguously interpreted as evidence of impaired memory of the contextfootshock association created by training such as that used in contextual fear conditioning (CFC).

The effects of BLA lesions and drug-induced inactivation have also been studied in experiments using inhibitory avoidance (IA), a task in which rats' retention of footshock-based learning is typically assessed by the animals' latencies to enter a compartment where they previously received footshock. Although animals may display freezing behavior on the retention test, freezing is not essential for evidence of memory of the training as assessed by retention test latencies. As BLA lesions typically do not prevent IA retention (Parent et al. 1995a; Roozendaal and McGaugh 1996; Roesler et al. 2002), the findings of studies using IA further question the hypothesis that the BLA is an essential locus of learning based on footshock training.

\footnotetext{
'Corresponding author.

E-MAIL danb@uci.edu; FAX (949) 824-2952.

Article and publication are at http://www.learnmem.org/cgi/doi/10.1101/ Im.64003.
}

IA and CFC training procedures (e.g., context-footshock training) are similar in that in both tasks the animals receive footshock in a particular context, but they differ in the specific training and retention testing procedures used. In IA training, the rats typically step into the shock compartment (or from a platform to a grid floor), whereas in CFC training the rats are placed into a compartment where footshock is delivered. It has been suggested that such procedural differences in training may engage different forms of memory with different neurobiological bases (Wilensky et al. 2000). Alternatively, the differences in the testing procedures typically used in IA and CFC experiments may be critical in determining the effects of BLA lesions. To investigate this issue, the present experiments trained rats by using Pavlovian CFC procedures but tested for retention by using IA procedures. That is, the rats' latencies to enter the shock compartment from an adjacent "safe" compartment, as well as repeated entrances of the shock compartment, were used to assess retention of the footshock training experience. In experiment 1 , freezing behavior on the retention test was also assessed. Experiments 1 and 2 investigated the effects, on retention, of BLA lesions induced prior to the training. Experiment 3 investigated the effects of intra-BLA infusions of the $\mathrm{GABA}_{\mathrm{A}}$ agonist muscimol administered before retention testing.

\section{MATERIALS AND METHODS}

\section{Experiment 1}

Subjects

Subjects were 36 male Sprague Dawley rats (Charles River, Wilmington, MA) weighing 225 to $250 \mathrm{~g}$ on arrival. The animals were individually housed in a temperature $\left(22^{\circ} \mathrm{C}\right)$ and light $(12$ $\mathrm{h} / 12$-h light/dark cycle; lights on at 7:00 a.m.) controlled vivarium. Food and water were provided ad libitum, and rats were acclimated to laboratory conditions for $1 \mathrm{wk}$ prior to surgery. All of the methods used complied with National Institutes of Health 
(NIH) guidelines and were approved by the University of California Irvine Institutional Animal Care and Use Committee.

\section{Surgical Procedures}

The rats were anesthetized with sodium pentobarbital $(50 \mathrm{mg} / \mathrm{kg}$ intraperitoneal [IP]) and received atropine sulfate $(0.4 \mathrm{mg} / \mathrm{kg}$ IP) to assist breathing. The rats were placed in a stereotaxic frame (Kopf Instruments). Bilateral BLA lesions were induced by infusing the neurotoxin $\mathrm{N}$-methyl-D-aspartate (NMDA; Sigma Chemical) through an infusion needle that was lowered into the BLA (anterior-posterior, $-2.8 \mathrm{~mm}$ from bregma; medial-lateral, \pm 5.0 $\mathrm{mm}$ from midline; dorsal-ventral, $-8.5 \mathrm{~mm}$ from the top of the skull; and nose bar, $-3.3 \mathrm{~mm}$ from interaural line; Paxinos and Watson 1998). The NMDA was dissolved into 0.9\% saline $(12.5$ $\mathrm{mg} / \mathrm{mL})$ and injected $(0.2 \mu \mathrm{L}, 0.55 \mu \mathrm{L} / \mathrm{min})$ through a needle $(30$ gauge, $17 \mathrm{~mm}$ ) attached to a $10-\mu \mathrm{L}$ syringe (Hamilton), by an automated Sage syringe pump (Orion Research). The injection needle was retained in place for $3 \mathrm{~min}$ postinfusion to minimize dorsal diffusion. Bilateral lesions were induced sequentially, and the scalp incision was closed with wound clips. Sham-lesioned animals received the same surgical treatment, with the exception that infusion needle was lowered to the level dorsal to the BLA (dorsal-ventral, $-6.5 \mathrm{~mm}$ from the top of the skull) and no solution was infused. The animals were allowed to recover for $7 \mathrm{~d}$ before the initiation of training.

\section{Behavioral Apparatus and Procedures}

The IA apparatus was a trough-shaped alley $(91 \mathrm{~cm}$ long, $6.4 \mathrm{~cm}$ wide at the bottom, $20 \mathrm{~cm}$ wide at the top) separated into two compartments by a sliding door that retracted into the floor. The light compartment was white and illuminated by a $14 \mathrm{~W}$ lamp, and the dark compartment was constructed of stainless steel walls and floor. The apparatus located was in a sound-attenuated, nonilluminated room.

The rats were first given habituation training in the apparatus. They were placed in the light compartment, with the door between the compartments open, and allowed to explore both compartments for $3 \mathrm{~min}$. For the training, $24 \mathrm{~h}$ later, the animals were placed in the dark compartment, with the door to the light compartment closed. Animals were allowed to explore the dark compartment for $1 \mathrm{~min}$ and were then given a footshock (1.0 $\mathrm{mA}, 1.0 \mathrm{sec})$. A second footshock was given after an additional minute, and then the animals were removed. For the retention testing $48 \mathrm{~h}$ later, the animals were placed into the light compartment facing the closed door. When the rat turned away from the door, the door was opened and the latency to enter the dark compartment was measured. The rat was allowed to explore both compartments for $600 \mathrm{sec}$, and time spent freezing was measured. Forty-eight hours later, animals were trained in continuous multiple trial IA (CMIA). Rats were placed in the light compartment and were allowed to enter the dark compartment. After entering the shock compartment, with all four paws, they received a mild footshock $(0.5 \mathrm{~mA}$, continuous) and were allowed to escape to the light compartment. They received a footshock on each re-entry of the dark compartment, and training continued until the rats remained in the light compartment for 200 consecutive seconds. The number of entries into the shock compartment was used as an additional measure of retention of the original training. Rats in the nonshocked groups received identical training as above, except that no footshocks were delivered during the training. Animals that received shock training in a different context were habituated as above but were trained in a clear Plexiglas box $(30 \times 30 \times 30 \mathrm{~cm})$ with a grid floor that was located in a different room that was well-lit. All other aspects of training and testing were identical.

\section{Statistics}

The results were assessed with one-way analyses of variance (ANOVA), using latency and CMIA shocks as between-subjects variables. Results were then analyzed by using Fisher's post hoc tests for assessing differences between individual groups. $P$ values of $<0.05$ were considered significant.

\section{Histology}

After the behavioral tests were completed, the rats were anesthetized with an overdose of sodium pentobarbital (100 mg/kg IP) and perfused intracardially with $0.9 \%$ saline and then $10 \%$ formaldehyde. Brains were then removed and placed in 10\% formaldehyde for a minimum of $4 \mathrm{~h}$ then were cryoprotected in a $30 \%$ sucrose solution. Sections of $40 \mu \mathrm{m}$ were taken with a freezing microtome and stained with cresyl violet. Slides were then examined under a light microscope.

\section{RESULTS}

\section{Histology}

Figure 1 includes photomicrographs of a typical sham lesion (Fig. $1 \mathrm{~A})$, the smallest lesion included (Fig. 1B), and the largest lesion included (Fig. 1C). The largest and smallest lesions included in experiment 1 are illustrated in Figure 2A. In some cases, lesions extended into the ventral caudate-putamen and part of the piriform cortex. The central nucleus was not included in the lesions. Only animals with bilateral BLA lesions were included in the analyses. Animals were excluded from the analyses if their lesions were either too small or extended significantly into adjacent brain regions.

\section{Habituation}

On the habituation session, all rats explored both compartments of the IA box, and none of the animals displayed freezing. The
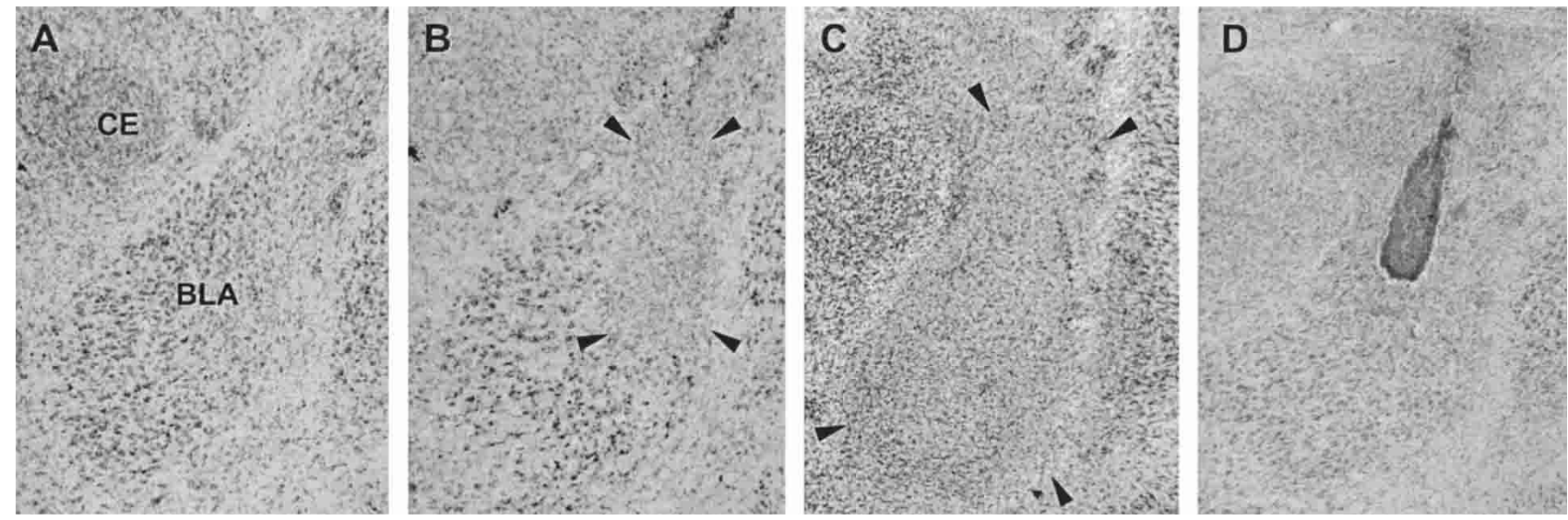

Figure 1 Photomicrographs of a sham lesion $(A)$, the smallest included lesion $(B)$, the largest included lesion $(C)$, and a representative needle track from the drug infusion in the BLA $(D)$. Arrows indicate the extent of the neurotoxic lesion. 


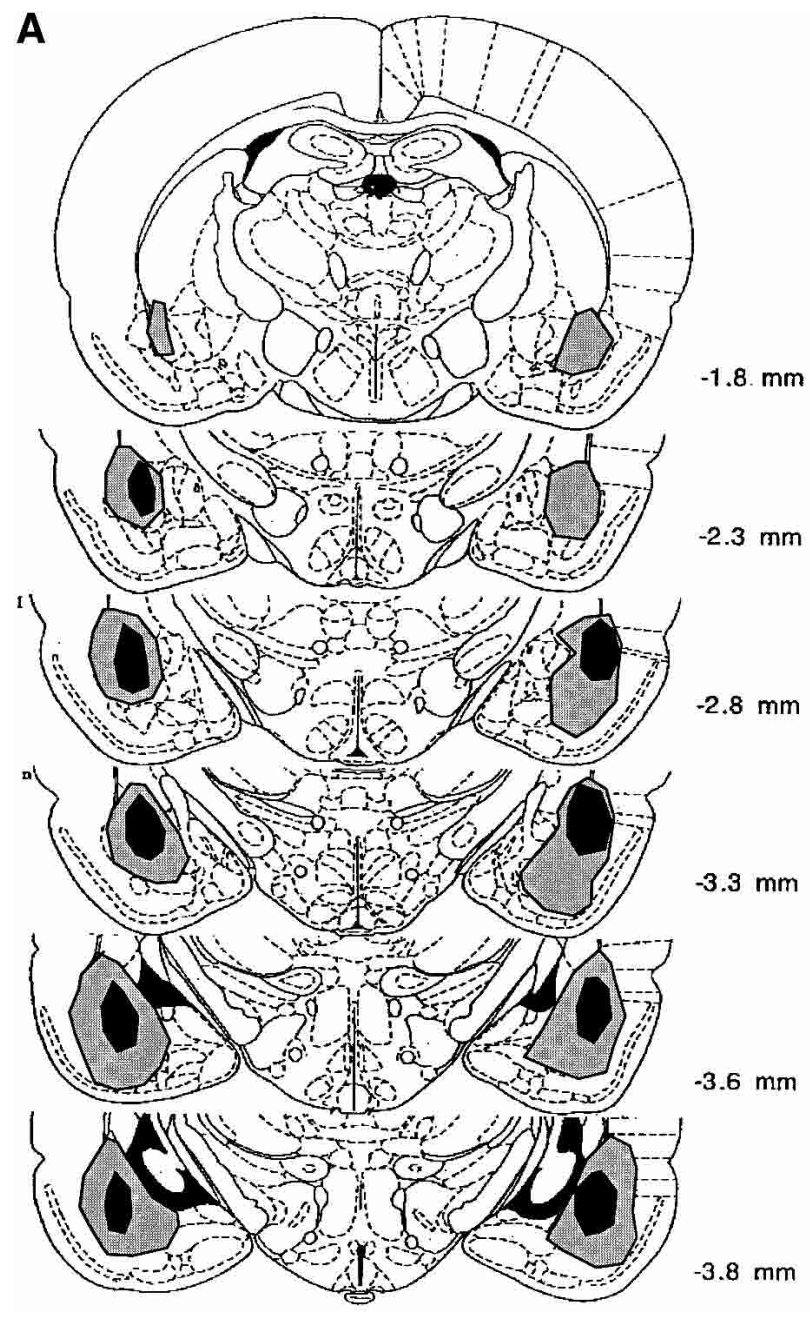

Figure 2 The largest and smallest BLA lesions included for experiment $1(A)$ and experiment $2(B)$.
B
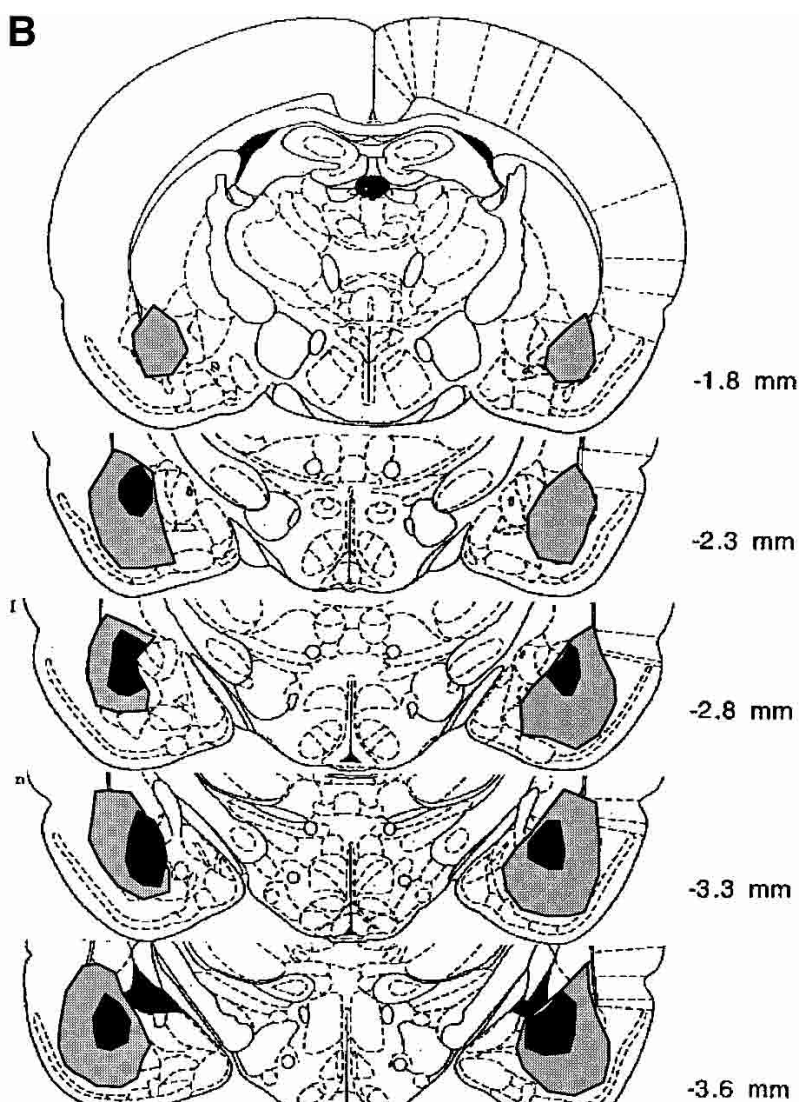

$-3.6 \mathrm{~mm}$

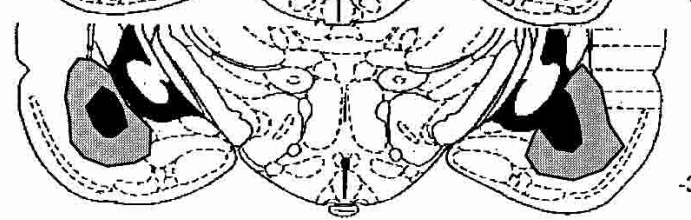

$-3.8 \mathrm{~mm}$
BLA and sham-lesioned rats did not differ in number of crossings between compartments and time spent in each compartment (data not shown).

\section{Retention Testing}

Figure 3 shows the latencies to enter the shock compartment on the 10-min retention test. The BLA-lesioned and sham-lesioned groups differed significantly in entrance latencies $\left[\mathrm{F}_{3,32}=31.55\right.$, $P<0.0001]$ and freezing $\left[\mathrm{F}_{3,32}=12.79, P<0.0001\right]$. Fisher's LSD post hoc tests indicated that the latencies of the BLA-lesioned rats given footshock training were shorter than those of the shamlesioned animals given footshock training $(P<0.0001)$. The retention latencies of the BLA-lesioned and sham-lesioned groups that did not receive footshock training did not differ $(P<0.05)$.

To confirm that the spared memory displayed by the BLAlesioned rats was context specific, some rats $(\mathrm{N}=$ six to nine animals per group) were shocked in a different context. These animals were tested in the same apparatus as the other groups, only the training context was different. BLA-lesioned animals displayed significantly more freezing $(P<0.05)$ and required significantly fewer shocks $(P<0.005)$ in CMIA training if they had received training in the same context, as opposed to a different context. In addition, sham animals had longer latencies $(P<0.005)$, significantly more freezing $(P<0.001)$, and fewer entries into the shock compartment in CMIA $(P<0.005)$ than did the sham controls shocked in the different context.
Figure 4 shows the percentage of time that animals displayed freezing on the 10-min retention test. The sham-controls given footshock training displayed more freezing than did shamnonshocked controls $(P<0.0001)$. The BLA-lesioned and shamlesioned groups that did not receive footshock training did not differ significantly in freezing behavior $(P>0.05)$. The BLA-lesioned group given footshock training displayed significantly more freezing than did BLA-lesioned rats not given shock training $(P<0.05)$ but significantly less freezing than did the shamlesioned group given footshock training $(P<0.01)$.

Overall, the groups differed significantly $\left[\mathrm{F}_{3,32}=33.06\right.$, $P<0.001]$ in the number of entries of the shock compartment during CMIA training (Fig. 5). The BLA-lesioned and sham-controls given prior shock training made fewer entries compared with those of the lesioned $(P<0.01)$ and sham groups $(P<0.01)$ given no prior shock training. The BLA-lesioned and sham-controls given prior shock did not differ significantly in entries of the shock compartment $(P>0.05)$.

In this experiment, the BLA-lesioned animals given footshock training displayed shorter retention latencies and reduced freezing behavior on the retention in comparison with the latencies and freezing seen in the sham-lesioned animals. Thus, the BLA lesions impaired retention performance as assessed by response latencies. However, the finding that the freezing displayed by the BLA-lesioned group given prior footshock training was greater than that of nonshocked animals indicates that the 


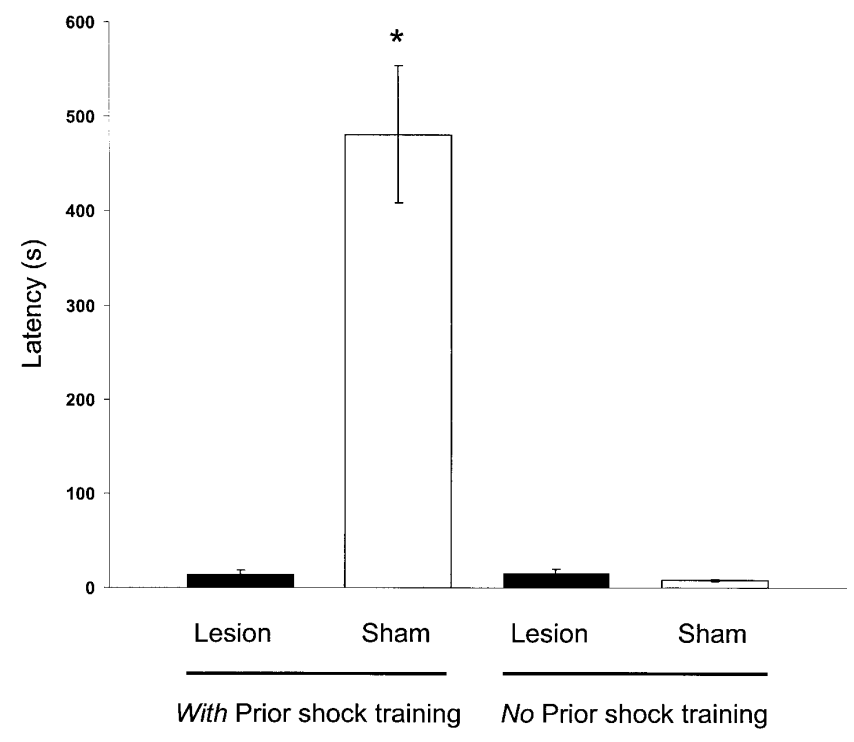

Figure 3 Latencies to enter the shock compartment during retention testing for sham and BLA-lesioned animals in experiment $1 .{ }^{*} P<0.001$ compared with sham (no prior shock training group; $N=6$ to 11 animals per group).

lesions did not prevent acquisition of the context-footshock association. In addition, the performance of the BLA-lesioned rats on CMIA did not differ significantly from that of the sham animals. The finding that BLA-lesioned animals given prior shock training made significantly fewer entries of the shock compartment on the CMIA, in comparison with BLA-lesioned animals and sham controls not given prior shock, provides strong evidence of spared memory of the original context-footshock training. The spared retention was not due to incomplete lesions in some of the animals. The small number of animals in subgroups with smaller and larger BLA lesions precluded statistical comparisons. However, animals with larger (i.e., complete) lesions displayed greater freezing (mean $=146, \mathrm{SE}=38 \mathrm{sec}$ ) than did nonshocked controls (mean $=1.7, \mathrm{SE}=0.2 \mathrm{sec}$ ). Furthermore, the animals with larger BLA lesions made fewer shock compartment entries (mean $=0.83, \mathrm{SE}=0.17 \mathrm{sec}$ ) than did the nonshocked controls (mean $=1.7, \mathrm{SE}=0.2 \mathrm{sec}$ ) on the CMIA test.

\section{Experiment 2}

In experiment 1 , the BLA-lesioned animals had impaired retention of context-footshock training, as indicated by shock-compartment entrance latencies. However, they had spared memory as indicated by freezing (reduced but not blocked), as well as the number of entries of the shock compartment on the CMIA test. As noted above, there is considerable evidence that BLA lesions impair freezing and enhance locomotor activity (Blanchard and Blanchard 1972; Ambrogi-Lorenzini et al. 1991; Burns et al. 1996; Vazdarjanova et al. 2001; Power and McGaugh 2002). Such effects may have contributed to the BLA lesion effect on freezing and retention latencies. The short retention latencies seen in the BLA-lesioned animals may have resulted from a reduced ability to freeze or inhibit responding in the presence of the shock-context and a consequent increase in escape responding. To address this issue further, the training procedures were altered for experiment 2. The animals were given no prior habituation and received only one footshock during training. In addition, the CMIA training was initiated on the 48 -h retention test. All other conditions were the same as those of experiment 1.

\section{MATERIALS AND METHODS}

\section{Subjects}

Subjects were 40 male Sprague Dawley rats (Charles River, Wilmington, MA) weighing 225 to $250 \mathrm{~g}$ on arrival. Animals were individually housed in a temperature $\left(22^{\circ} \mathrm{C}\right)$ and light $(12-\mathrm{h} /$ 12-h light/dark cycle; lights on at 7:00 a.m.) controlled vivarium. Food and water were provided ad libitum, and rats were acclimated to laboratory conditions for $1 \mathrm{wk}$ prior to surgery.

\section{Surgical Procedure}

The rats received bilateral BLA lesions as described above.

\section{Behavioral Apparatus and Procedure}

The IA apparatus was the same as described above. However, unlike the procedure in experiment 1 , the animals were not given a habituation session prior to the training. For the context-footshock training, the animals were placed in the dark compartment, with the sliding door to the lighted compartment closed. The animals were allowed to explore the dark compartment for $15 \mathrm{sec}$ and were then given a single footshock $(1.0 \mathrm{~mA}, 1.0 \mathrm{sec})$. They were removed from the box $5 \mathrm{sec}$ later and returned to their home cages. Forty-eight hours later, the animals were placed in the lighted compartment facing the closed door. After the rat turned away from the door, the door was opened, and the latency to enter the dark compartment was measured. The animals were then immediately trained in CMIA. On each subsequent entry of the dark compartment they received a mild footshock $(0.5 \mathrm{~mA}$, continuous) and were allowed to escape to the light compartment. Training continued until the rats remained in the light compartment for 200 consecutive seconds. The number of entries into the shock compartment was recorded and used as a measure of retention of the original training.

Rats in the nonshocked groups received identical training as above, except no footshock was delivered during the original training.

\section{Histology}

After behavioral tests were completed, rats were anesthetized with an overdose of sodium pentobarbital (100 mg/kg IP), and slides were prepared as described above. Slides were then examined under a light microscope to verify lesion accuracy.

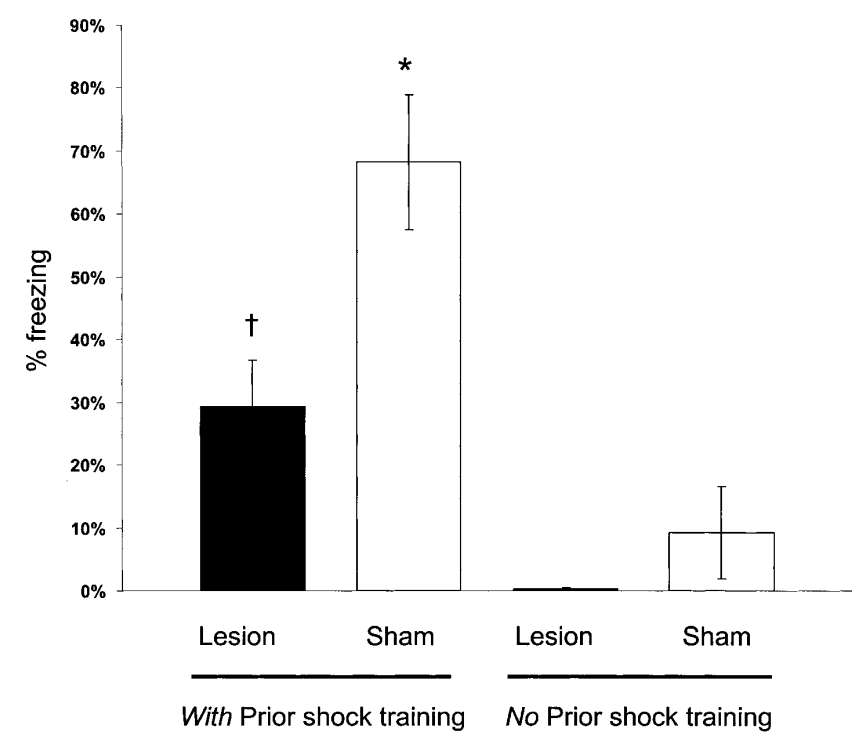

Figure 4 Freezing behavior during the 10-min retention testing $\dagger P<0.05$ compared with lesion (no prior shock training group); ${ }^{*} P<0.05$ compared with sham (no prior shock training group; $N=6$ to 11 animals per group). 


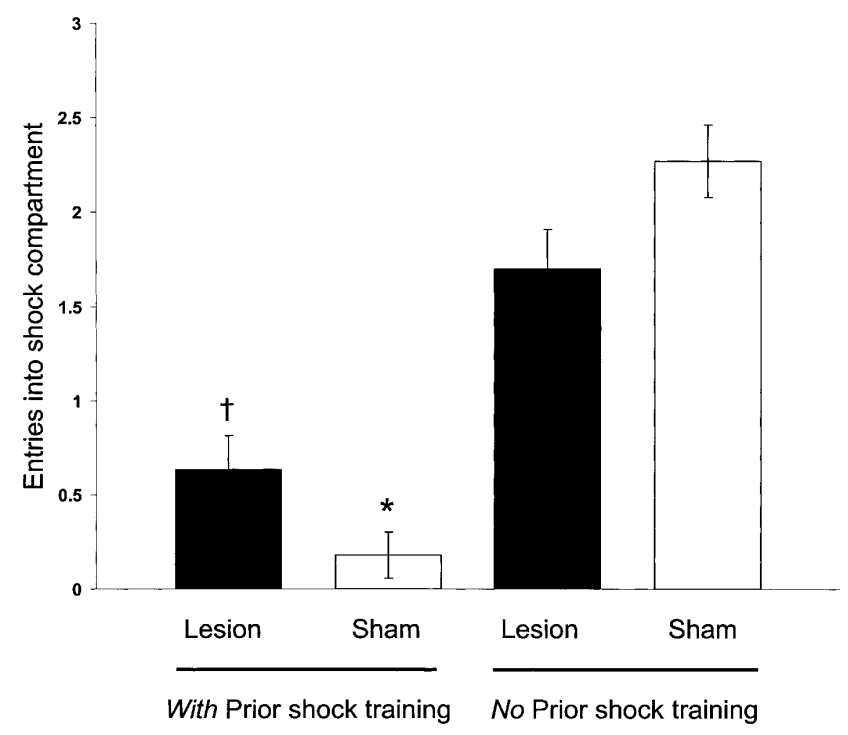

Figure $5 \mathrm{CMIA}$ trials needed to reach the 200-sec criterion for shamand BLA-lesioned rats. $\uparrow P<0.001$ compared with lesion (no prior shock training group); ${ }^{*} P<0.0001$ compared with the sham (no prior shock training group; $N=6$ to 11 animals per group).

\section{RESULTS}

\section{Histology}

The largest and smallest lesions included in the study are shown in Figure 2B. As in the previous experiment, only animals with bilateral BLA lesions were included in the analyses. Animals were excluded from the analyses if the lesions were either too small or extended significantly into adjacent brain regions.

\section{Retention Testing}

Figures 6 and 7 show retention latency and CMIA results on the 48-h retention test. The latencies of both the BLA-lesioned and sham controls given footshock shock training differed from those of lesioned and sham groups not given shocks during training $\left[\mathrm{F}_{1,36}=33.54, P<0.0001\right]$. Similarly, the groups given prior footshock training differed from those not given prior shock training in number of entries of the shock compartment during the CMIA training $\left[\mathrm{F}_{1,36}=25.36, P<0.0001\right]$. Post hoc tests confirmed that, for the shock and no-shock training conditions, the latencies of the BLA-lesioned rats did not differ from those of the sham-lesioned rats $(P>0.05$ for both conditions). Both BLA- and sham-lesioned rats had significantly longer retention latencies with prior shock training than did their respective controls that did not receive shock training $(P<0.005$ for lesioned; $P<0.001$ for sham animals). In addition, on the CMIA training, both the BLA- and sham-lesioned animals with prior shock training made significantly fewer entries into the shock compartment in comparison with those of the BLA-lesioned and sham controls given no prior shock training $(P<0.01$ for BLA-lesioned; $P<0.0001$ for sham animals).

The findings of experiment 2 indicate that the BLA lesions did not prevent retention of context-footshock training as assessed either by latencies to enter the shock compartment or by entries of the shock compartment on the CMIA training. As in experiment 1, the spared retention was not due to incomplete lesions in some of the animals. Animals with larger (i.e., complete) lesions had longer latencies than did the nonshocked controls $(P<0.05)$. Furthermore, the animals with larger BLA lesions made fewer shock compartment entries than did the nonshocked controls $(P<0.05)$ on the CMIA test.

\section{MATERIALS AND METHODS}

\section{Experiment 3}

\section{Subjects}

Subjects were 27 male Sprague Dawley rats (Charles River, Wilmington, MA) weighing 225 to $250 \mathrm{~g}$ on arrival. Animals were individually housed as described above.

\section{Surgical Procedure}

The rats were anesthetized with sodium pentobarbital $(50 \mathrm{mg} / \mathrm{kg}$ IP), and received atropine sulfate $(0.4 \mathrm{mg} / \mathrm{kg} \mathrm{IP})$ to assist breathing. The rats were placed in a stereotaxic frame (Kopf Instruments). After the skull was exposed, holes were drilled for the placement of bilateral cannula (15 $\mathrm{mm}, 23$-gauge). The cannula were lowered at coordinates $2.8 \mathrm{~mm}$ posterior to bregma and 5.0 $\mathrm{mm}$ lateral to the midline, just dorsal to the BLA $(-6.5 \mathrm{~mm}$ from the skull), and fixed in place with dental cement and two jewel screws attached to the skull. The incision was closed with wound clips, and 15-mm-long stylets were inserted in the cannula to prevent clogging. The animals were allowed to recover for $7 \mathrm{~d}$ before the initiation of training.

\section{Behavioral Apparatus and Procedure}

Animals were handled on the $3 \mathrm{~d}$ prior to training for $60 \mathrm{sec}$ each day, to allow habituation to the pretesting drug administration procedure. The IA apparatus was the same as described above. The rats were first given habituation training in the apparatus. They were placed in the light compartment, with the door between the compartments open, and allowed to explore both compartments for $3 \mathrm{~min}$. For the context-footshock training, 24 $\mathrm{h}$ later, the animals were placed in the dark compartment, with the door to the light compartment closed. Animals were allowed to explore the dark compartment for $15 \mathrm{sec}$ and were then given a footshock $(0.8 \mathrm{~mA}, 1.0 \mathrm{sec})$. A second identical footshock was given after an additional $30 \mathrm{sec}$, and the animals were removed $15 \mathrm{sec}$ later, for a total time of $1 \mathrm{~min}$ in the compartment. Fortyeight hours later, the animals received infusions of either muscimol or saline and retained in their home cages to allow for drug activation. After $30 \mathrm{~min}$, the rat was placed in the lighted compartment facing the closed door. After the rat turned away from the door, the door was opened, and the latency to enter the dark

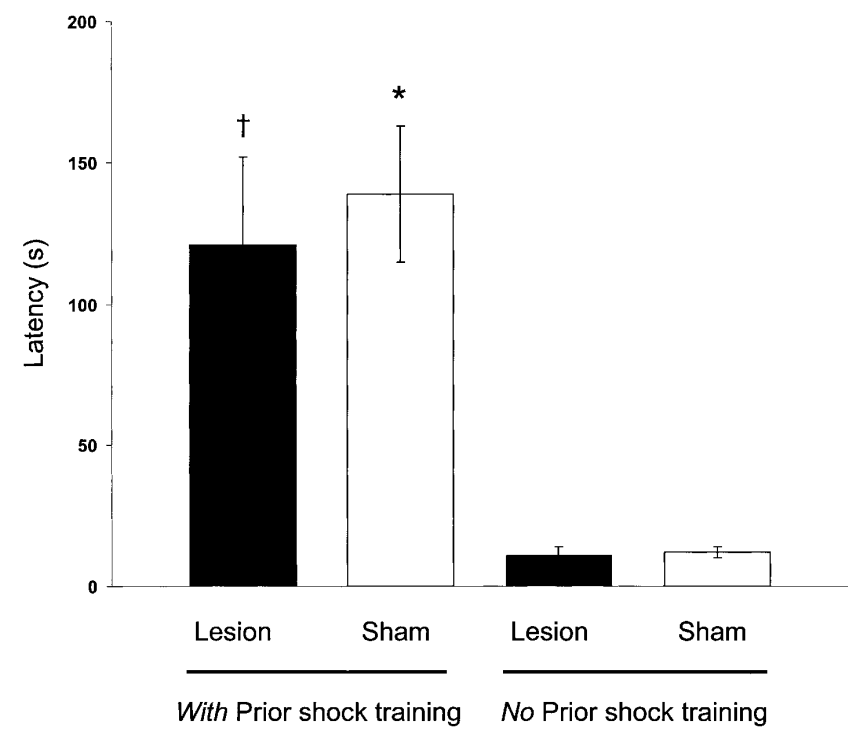

Figure 6 Latencies to enter the shock compartment during CMIA testing in experiment 2 for sham- and BLA-lesioned animals. $\dagger P<0.005$ compared with lesion (no prior shock training group); ${ }^{*} P<0.0001$ compared with sham (no prior shock training group; $N=8$ to 13 animals per group). The maximum latency was $200 \mathrm{sec}$. 


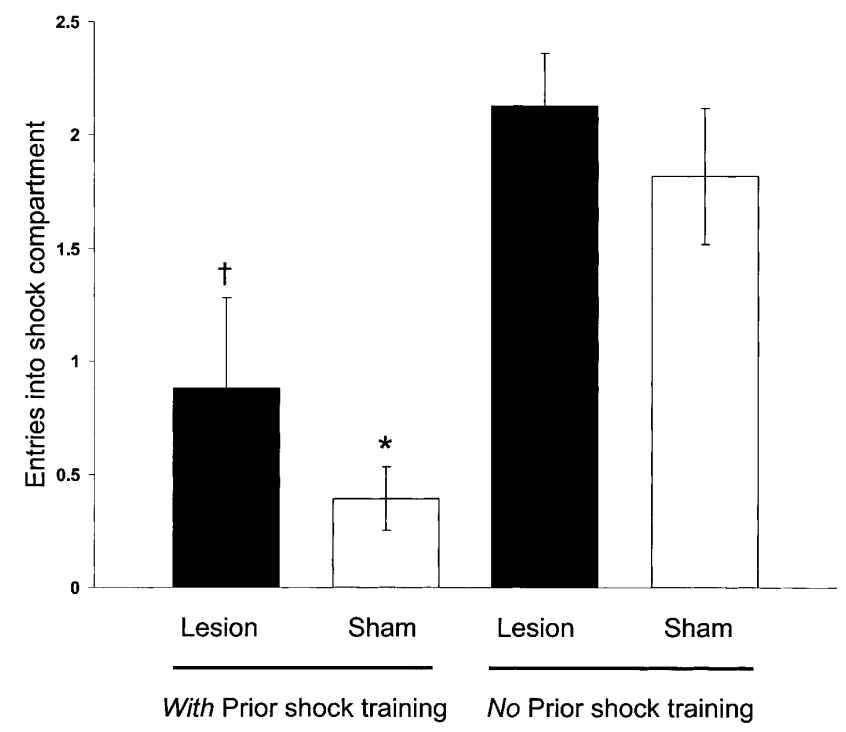

Figure 7 CMIA trials needed to reach the 200-sec criterion for sham and BLA-lesioned rats in experiment 2. $\dagger P<0.005$ compared with lesion (no prior shock training group); ${ }^{*} P<0.0001$ compared with sham (no prior shock training group; $N=8$ to 13 animals per group).

compartment was measured. As in experiment 2 , the animals were then immediately trained in CMIA, as described above.

\section{Drugs and Infusion Procedures}

Muscimol (Sigma) was dissolved in saline and made fresh before each experiment. Bilateral pretesting infusions of saline or muscimol were made through 30 -gauge injection needles connected to a $10 \mu \mathrm{L}$ Hamilton syringe by polyethylene tubing. The needles protruded $2 \mathrm{~mm}$ beyond the tip of the cannula to reach the BLA. A total of 1.1 nmole in volume of $0.2 \mu \mathrm{L}$ per side was infused by an automated syringe pump (Sage Instruments) over a period of $22 \mathrm{sec}$. The needles were retained in place for an additional $60 \mathrm{sec}$ to allow for diffusion within the BLA.

\section{Histology}

After behavioral tests were completed, rats were anesthetized with an overdose of sodium pentobarbital (100 mg/kg IP), and slides were prepared as described above. Slides were then examined under a light microscope to verify cannula placement.

\section{RESULTS}

\section{Histology}

Figure 1D is a photomicrograph of a representative example of an intra-BLA infusion needle track. Only animals with bilateral needle tracks in the BLA were included in the analyses.

\section{Retention Testing}

Figure 8 shows the latencies to enter the shock compartment on the retention test. The groups differed significantly in entrance latencies $\left[\mathrm{F}_{3,23}=8.40, P<0.001\right]$. Fisher's LSD post hoc tests indicated that the latencies of the saline-infused rats given footshock training were longer than those of the muscimol-infused animals given footshock training $(P<0.001)$. The retention latencies of the muscimol-infused and saline-infused groups that did not receive footshock training did not differ $(P>0.05)$.

During CMIA training, the groups differed significantly $\left[\mathrm{F}_{3,23}=6.01, P<0.005\right]$ in the number of entries into the shock compartment (Fig. 9). Both muscimol- and saline-infused rats had made significantly fewer entries into the shock compartment in comparison with those of the muscimol- and saline-infused controls given no prior shock training $(P<0.05$ for muscimol;
$P<0.05$ for saline animals). For both the shock and no-shock training conditions, the number of entries of the muscimol-infused rats did not differ from those of the saline-infused rats ( $P>0.05$ for both conditions).

\section{DISCUSSION}

Experiments 1 and 2 examined the effects of bilateral BLA lesions induced before training on the retention of memory for contextfootshock training. Experiment 3 examined the effects of infusions of the $\mathrm{GABA}_{\mathrm{A}}$ agonist muscimol administered prior to testing the retention of context-footshock training. In experiment 1 , the BLA lesions impaired IA retention performance but did not block memory as assessed by freezing or number of entries of the shock compartment on the retention test. In experiment 2, BLA lesions did not block retention as assessed by either IA or number of entries of the shock compartment. The findings of experiment 3 were similar to those of experiment 1: Pretesting intra-BLA infusions of muscimol impaired IA retention performance but did not block retention as assessed by number of entries of the shock compartment. In addition, the poor retention performance of control animals shocked in a different context provides evidence of the context specificity of the memory. Thus, these findings provide additional evidence that an intact and functioning BLA is not required for acquiring, storing, and retrieving memory of context-footshock training. These results are consistent with previous evidence indicating that disruption of BLA functioning does not block the acquisition or retention of aversively based training (Selden et al. 1991; Parent et al. 1994, 1995a,b; Killcross et al. 1997; Vazdarjanova and McGaugh 1998, 1999; Cahill et al. 2000; Lehmann et al. 2000, 2003).

In experiment 1 , rats were habituated to the IA box and given two footshocks in the shock compartment the following day. When tested $48 \mathrm{~h}$ later, the BLA-lesioned animals, compared with sham-lesioned animals, had shorter latencies to enter the shock compartment and displayed less freezing. However, they displayed significantly more freezing than did nonshocked controls. BLA lesions did not block savings of prior shock training, as indicated by fewer entries of the shock compartment on the CMIA retention test. In experiment 2 , the rats received no prior habituation to the apparatus. They received one footshock in the

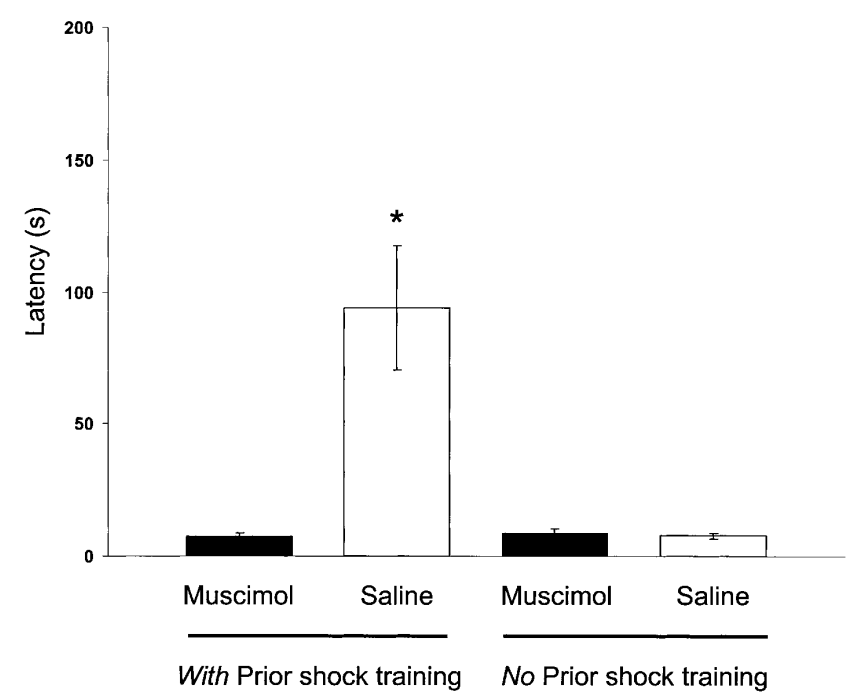

Figure 8 Latencies to enter the shock compartment during CMIA testing in experiment 3 for muscimol- and saline-infused rats. ${ }^{*} P<0.001$ compared with saline (no prior shock training group; $N=$ six to nine animals per group). The maximum latency was $200 \mathrm{sec}$. 


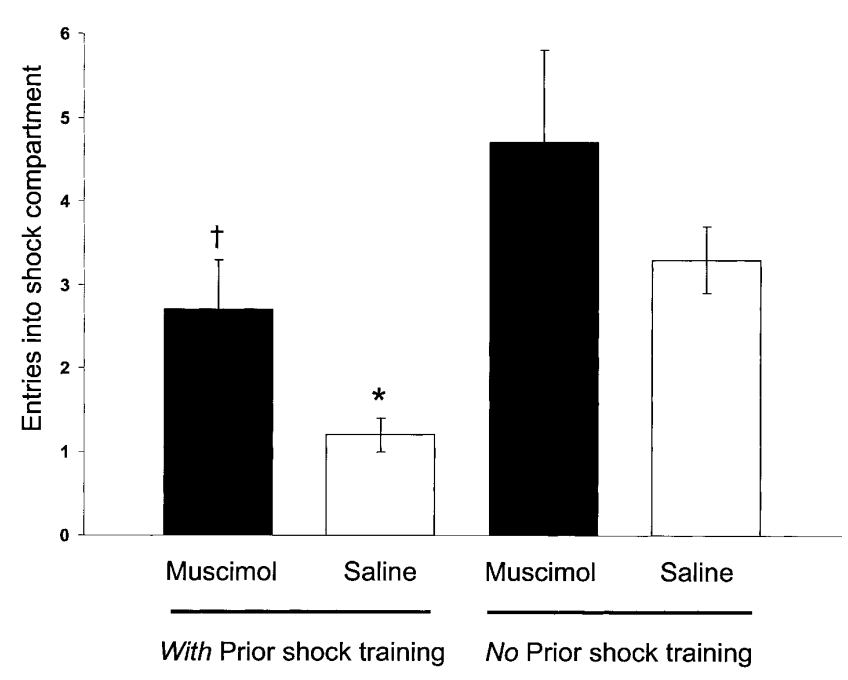

Figure 9 CMIA trials needed to reach the 200-sec criterion for muscimol- and saline-infused rats in experiment $3 . \dagger P<0.05$ compared with muscimol (no prior shock training group); ${ }^{*} P<0.05$ compared with saline (no prior shock training group; $N=$ six to nine animals per group).

dark compartment of the IA box, and were tested 2 d later. Immediately after retention testing, the rats received CMIA training. The retention of the BLA-lesioned animals was not impaired compared with that of sham-lesioned animals, as assessed by retention latencies and CMIA retention performance. In addition, in comparison with controls not given prior shock, the lesioned animals had longer latencies and made fewer entries of the shock compartment on the CMIA test.

In experiment 1 , the controls had long $(\sim 500 \mathrm{sec})$ retention latencies, whereas the BLA-lesioned animals had very short latencies. There is extensive evidence indicating that amygdalalesioned animals have increased locomotor activity (Blanchard and Blanchard 1972) and are impaired in expressing freezing behavior (Vazdarjanova et al. 2001). With the training conditions used in experiment 1 , prior habituation and two footshocks for the context-footshock training, the BLA lesions may have reduced the animals' ability to express freezing and inhibit responding in the presence of apparatus contextual cues associated with the footshock training and increased the animals' tendencies to use active escape responses. The findings of experiment 2 are consistent with this hypothesis. In experiment 2 , in which the animals received no prior habituation and only one footshock on the context-footshock training, the lesioned animals had longer retention latencies and did not differ significantly from sham-control animals.

Experiment 3 used training conditions similar to those of experiment 1 . The animals received prior habituation and received two training footshocks. Like the effect of BLA lesions found in experiment 1, intra-BLA infusions of muscimol prior to testing resulted in shorter retention latencies compared with those of saline-infused controls. Thus, retention performance assessed by this measure was impaired. However, like the findings of BLA lesions, the muscimol infusions did not impair retention of the context-footshock training, as indicated by number of entrances of the shock compartment where they received shock on each entrance. Both the muscimol-infused rats and the salineinfused rats given prior shock training made fewer entrances of the shock compartment than did muscimol- and saline-infused rats that did not receive prior shock training. These findings indicate that muscimol infused into the BLA prior to the retention test did not block memory of the prior footshock training. The similarity of the effects of BLA lesions induced prior to training and intra-BLA infusions of muscimol administered prior to testing provides further evidence indicating that the BLA lesions did not impair acquisition of context-footshock association. Furthermore, the finding that muscimol infused into the BLA prior to retention testing did not block memory of prior footshock training indicates that it is unlikely that the spared retention of context-footshock training in BLA-lesioned rats resulted from some other brain are taking over the functions of the lesioned BLA to enable acquisition of the context-footshock association. Of course, it remains possible that some other brain area might take over when the BLA is disabled, permanently or temporarily, to enable memory retrieval. However, consideration of this possibility would also require the conclusion that the BLA is not critical for either the acquisition or expression of memory of contextfootshock training.

In the present experiments, CFC procedures were used for training. That is, the animals were placed directly into the shock compartment. The term CFC is used because it is conventionally used to refer to context-footshock training. However, the present studies do not address the issue of whether the expression of memory of such training is based on fear, as that would require a definition of fear that is not circularly defined by the behavioral measures typically used to infer fear. CFC studies typically use freezing behavior to assess memory. In typical studies of IA, the rats are placed into the safe compartment and allowed to step into the compartment (or to step down from a platform to a grid floor) where they receive a footshock. Memory is typically assessed by the latencies to enter the shock compartment on a retention test. Because the animals are allowed to enter the shock compartment on the IA training trial, it has been suggested that IA training may be based on instrumental learning and thus engage neurobiological systems that are different from those engaged by Pavlovian CFC training (Wilensky et al. 2000). The present findings clearly indicate that IA expressed on the retention test does not require an instrumental response on the training. Thus, the essential difference between IA and CFC appears to be the behavioral measures typically used to assess retention of the training. The present findings indicating that BLA lesions did not block memory of context-footshock training, as indicated by several response measures, are consistent with extensive evidence that BLA lesions do not block memory for IA training, and, thus an intact BLA is not essential for acquiring and retaining aversively based memories.

\section{ACKNOWLEDGMENTS}

We thank Patrick Wong and Kristi Blake for their excellent technical assistance and Nancy Collett for assistance in preparation of the manuscript. Supported by NIH grant MH 12526 (J.L.M.).

The publication costs of this article were defrayed in part by payment of page charges. This article must therefore be hereby marked "advertisement" in accordance with 18 USC section 1734 solely to indicate this fact.

\section{REFERENCES}

Ambrogi-Lorenzini, C., Baldi, E., Bucherelli, C., Giachetti, A., and Tassoni, G. 1991. Effects of nucleus basolateralis amygdalae neurotoxic lesions on some spontaneous activities in the rat. Physiol. Behav. 50: 1215-1219.

Blanchard, D.C. and Blanchard, R.J. 1972. Innate and conditioned reactions to threat in rats with amygdaloid lesions. J. Comp. Physiol. Psychol. 81: 281-290.

Burns, L.H., Annett, L., Kelley, A.E., Everitt, B.J., and Robbins, T.W 1996. Effects of lesions to amygdala, ventral subiculum, medial prefrontal cortex, and nucleus accumbens on the reaction to novelty: Implication for limbic-striatal interactions. Behav. Neurosci. 110: $60-73$.

Cahill, L., Vazdarjanova, A., and Setlow, B. 2000. The basolateral amygdala complex is involved with, but is not necessary for, rapid acquisition of Pavlovian "fear conditioning." Eur. J. Neurosci. 
12: 3044-3050.

Davis, M., Walker, D.L., and Lee, Y. 1997. Amygdala and bed nucleus of the stria terminalis: Differential roles in fear and anxiety measured with the acoustic startle reflex. Philos. Trans. R. Soc. Lond. B Biol. Sci. 352: 1675-1687.

Killcross, S., Robbins, T.W., and Everitt, B.J. 1997. Different types of fear-conditioned behaviour mediated by separate nuclei within amygdala. Nature 388: 377-380.

Kim, J.J., DeCola, J.P., Landeira-Fernandez, J., and Fanselow, M.S. 1991. $\mathrm{N}$-methyl-D-aspartate receptor antagonist APV blocks acquisition but not expression of fear conditioning. Behav. Neurosci. 105: 126-133.

LeDoux, J.E. 1995. Emotion: Clues from the brain. Annu. Rev. Psychol. 46: $209-235$

Lehmann, H., Treit, D., and Parent, M.B. 2000. Amygdala lesions do not impair shock-probe avoidance retention performance. Behav. Neurosci. 114: 107-116.

. 2003. Spared anterograde memory for shock-probe fear conditioning after inactivation of the amygdala. Learn. Mem. 10: $261-269$.

Maren, S. 1998. Overtraining does not mitigate contextual fear conditioning deficits produced by neurotoxic lesions of the basolateral amygdala. J. Neurosci. 18: 3088-3097.

Maren, S. and Fanselow, M.S. 1996. The amygdala and fear conditioning: Has the nut been cracked? Neuron 16: 237-240.

Maren, S., Aharonov, G., and Fanselow, M.S. 1996a. Retrograde abolition of conditional fear after excitotoxic lesions in the basolateral amygdala of rats: Absence of a temporal gradient. Behav. Neurosci. 110: 718-726.

Maren, S., Aharonov, G., Stote, D.L., and Fanselow, M.S. 1996b. $\mathrm{N}$-methyl-D-aspartate receptors in the basolateral amygdala are required for both acquisition and expression of conditional fear in rats. Behav. Neurosci. 110: 1365-1374.

Parent, M.B., West, M., and McGaugh, J.L. 1994. Memory of rats with amygdala lesions induced 30 days after footshock-motivated escape training reflects degree of original training. Behav. Neurosci. 108: $1080-1087$.

Parent, M.B., Avila, E., and McGaugh, J.L. 1995a. Footshock facilitates the expression of aversively motivated memory in rats given post-training amygdala basolateral complex lesions. Brain Res. 676: $235-244$.

Parent, M.B., Quirarte, G.L., Cahill, L., and McGaugh, J.L. 1995b. Spared retention of inhibitory avoidance-learning after posttraining amygdala lesions. Behav. Neurosci. 109: 803-807.

Paxinos, G. and Watson, C. 1998. The rat brain in stereotaxic coordinates, 4th ed. Academic Press, San Diego.

Phillips, R.G. and LeDoux, J.E. 1992. Differential contribution of amygdala and hippocampus to cued and contextual fear conditioning. Behav. Neurosci. 106: 274-285.

Power, A.E. and McGaugh, J.L. 2002. Cholinergic activation of the basolateral amygdala regulates unlearned freezing behavior in rats. Behav. Brain Res. 134: 307-315.

Roesler, R., Roozendaal, B., and McGaugh, J.L. 2002. Basolateral amygdala lesions block the memory-enhancing effect of 8-Br-cAMP infused into the entorhinal cortex of rats after training. Eur. J. Neurosci. 15: 905-910.

Roozendaal, B. and McGaugh, J.L. 1996. Amygdaloid nuclei lesions differentially affect glucocorticoid-induced memory enhancement in an inhibitory avoidance task. Neurobio. Learn. Mem. 65: 1-8.

Schafe, G.E., Nadel, N.V., Sullivan, G.M., Harris, A., and LeDoux, J.E. 1999. Memory consolidation for contextual and auditory fear conditioning is dependent on protein synthesis, PKA, and MAP kinase. Learn. Mem. 6: 97-110.

Selden, N.R.W., Everitt, B.J., Jarrard, L.E., and Robbins, T.W. 1991 Complementary roles for the amygdala and hippocampus in aversive conditioning to explicit and contextual cues. Neuroscience 42: $335-350$.

Vazdarjanova, A. and McGaugh, J.L. 1998. Basolateral amygdala is not critical for cognitive memory of contextual fear conditioning. Proc. Natl. Acad. Sci. 95: 15003-15007.

. 1999. Basolateral amygdala is involved in modulating consolidation of memory for classical fear conditioning. J. Neurosci. 19: 6615-6622.

Vazdarjanova, A., Cahill, L., and McGaugh, J.L. 2001. Disrupting basolateral amygdala function impairs unconditioned freezing and avoidance in rats. Eur. J. Neurosci. 14: 709-718.

Wilensky, A.E., Schafe, G.E., and LeDoux, J.E. 2000. The amygdala modulates memory consolidation of fear-motivated inhibitory avoidance learning but not classical fear conditioning. J. Neurosci. 20: 7059-7066.

Received June 6, 2003; accepted in revised form September 25, 2003.

\section{Learning \& Memory}




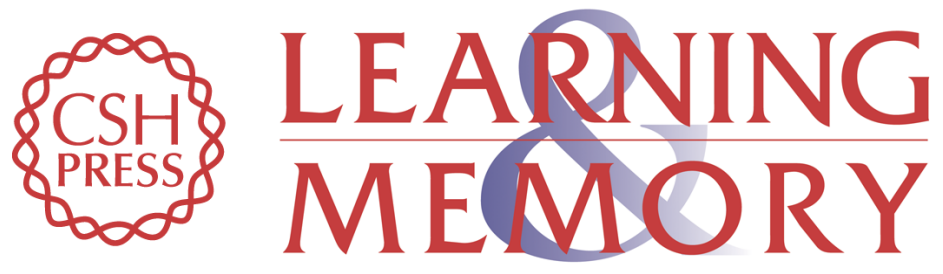

\section{Basolateral Amygdala Lesions Do Not Prevent Memory of Context-Footshock Training}

Daniel J. Berlau and James L. McGaugh

Learn. Mem. 2003, 10:

Access the most recent version at doi:10.1101/lm.64003

References This article cites 26 articles, 6 of which can be accessed free at:

http://learnmem.cshlp.org/content/10/6/495.full.html\#ref-list-1

License

Email Alerting Receive free email alerts when new articles cite this article - sign up in the box at the Service top right corner of the article or click here. 